\title{
Control design for axial flux permanent magnet synchronous motor which operates above the nominal speed
}

Xuan Minh Tran*, Nhu Hien Nguyen, Quoc Tuan Duong

Thai Nguyen University of Technology, Vietnam

\author{
A R T I C L E IN F O \\ Article history: \\ Received: 22 March, 2017 \\ Accepted: 07 April, 2017 \\ Online: 20 April, 2017
}

Keywords:

AFPM motor

Optimal control above nominal

speed

\begin{abstract}
A B S T R A C T
The axial flux permanent magnet synchronous motor (AFPM motor) using magnet bearings instead of ball-bearings at both two shaft ends could allow rotational speed of shaft much greater than nominal speed. One of the solutions to increase motor speed higher than its nameplate speed is reducing rotor's pole magnetic flux of rotor $\left(\Psi_{p}\right)$. This paper proposes a method to boost the speed of AFPM motor above nominal speed by adding a reversed current $i_{s d}$ of $\left(\Psi_{p}\right)$.
\end{abstract}

\section{AFPM Motor}

\subsection{Structure}

In terms of structure, the AFPM motor has its own particular specialists, in details, the stator module may include several types: A single module has one winding set and a dual module has two sets of winding sharing a common core and back-to-back establishment. Similarly, a single rotor module includes only one permanent magnet on one side, and in dual module one, both sides have permanent magnets leaning against each other.

In this research, an object with two single module stator outside and one dual module rotor inside is designated as shown in Figure 1 .

\subsection{Principle of Operation}

When a three-phase voltage is granted to stator coils, different currents are generated (including current $i_{q}$ ) flowing inside, they will interact with the magnetics of rotor to generate torque $(M)$ and the currents in phase windings (component $i_{d}$ ) of stator generate thrust and drag $(F)$ based on the principle of the electromagnet. Thanks to special structure and above-mentioned operating principle, the rotor of the motor will not generate axial displacement although both ends of the shaft have magnetic bearings. It allows the absence of additional axial movement block

\footnotetext{
* Xuan Minh Tran, Thai Nguyen University of Technology, Vietnam

E-mail: tranxuanminh@tnut.edu.vn
}

of the rotor, therefore, the motor structure is being compact. Due to the way of winding roll, the rotational magnetic field generates torques $M_{1}$ and $M_{2}$ on the same direction on the rotor shaft and generates thrust-drag forces $F 1$ and $F 2$ between the rotor and the stator on opposite direction. The total torque $\left(M=M_{1}+M_{2}\right)$ is the summation of the torques but the total force is the difference of the axial attractive forces $\left(F=F_{1}-F_{2}\right)$.

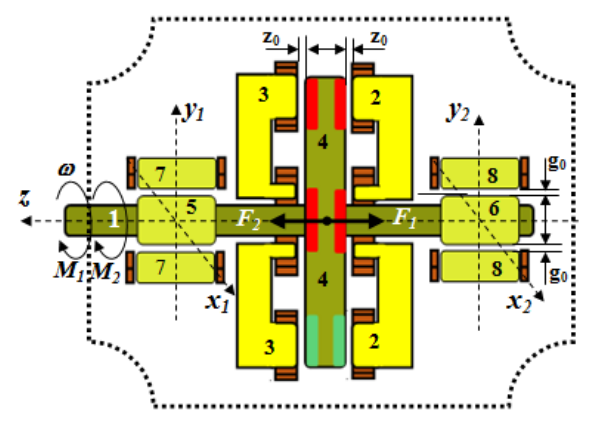

Figure 1: The AFPM motor section with magnetic bearing at both ends integrated (1: The shaft; 2, 3: the stator and the winding of left side and right side of motor; 4: the permanent magnetic rotor of motor; 5, 6: the magnetic bearing rotors on left and right sides; 7, 8: the stator and the winding of magnetic bearing on left and right sides; $z_{0}, g_{0}:$ the nominal gaps between the rotor and stator of motor with magnetic bearings)

From the structure and the principle of operation mentioned above, AFPM motor can be considered as two motors that have a common rotor or share a common sharp. 


\section{Mathematical Model of the AFPM Motor}

According to $[1,2,3]$, the mathematical model of AFPM motor was developed in $d q$ coordinate system, as presented on (1). The indicator 1 and 2 are present for the left side motor and right side motor, respectively.

$$
\begin{aligned}
& u_{s d 1}=R_{s} i_{s d 1}+L_{s d 1} \frac{d i_{s d 1}}{d t}-\omega_{s} L_{s q 1} i_{s q 1} \\
& u_{s q 1}=R_{s} i_{s q 1}+L_{s q 1} \frac{d i_{s q 1}}{d t}+\omega_{s} L_{s d 1} i_{s d 1}+\omega_{s} \psi_{p} \\
& u_{s d 2}=R_{s} i_{s d 2}+L_{s d 2} \frac{d i_{s d 2}}{d t}-\omega_{s} L_{s q 2} i_{s q 2} \\
& u_{s q 2}=R_{s} i_{s q 2}+L_{s q 2} \frac{d i_{s q 2}}{d t}+\omega_{s} L_{s d 2} i_{s d 2}+\omega_{s} \psi_{p} \\
& m_{M 1}=\frac{3}{2} z_{p}\left[\psi_{p} i_{s q 1}+i_{s d 1} i_{s q 1}\left(L_{s d 1}-L_{s q 1}\right)\right] \\
& m_{M 2}=\frac{3}{2} z_{p}\left[\psi_{p} i_{s q 2}+i_{s d 2} i_{s q 2}\left(L_{s d 2}-L_{s q 2}\right)\right] \\
& m_{\Sigma}=m_{M 1}+m_{M 2}=m_{m}+\frac{J}{z_{p}} \frac{d \omega}{d t} \\
& F_{\Sigma}=k_{1}\left(i_{2 d}-i_{d}\right)+k_{1}\left(i_{2 d}-i_{1 d}\right) z-k_{2} z \\
& k_{1}=2 \frac{\mu_{0}^{2} N^{2}}{g_{0}^{2}} \psi_{p} ; k_{2}=2 \frac{\mu_{0}}{S_{p} g_{0}} \psi_{p}^{2} .
\end{aligned}
$$

The stucture of AFPM motor as methematical model (1) is presented in Figure 2.

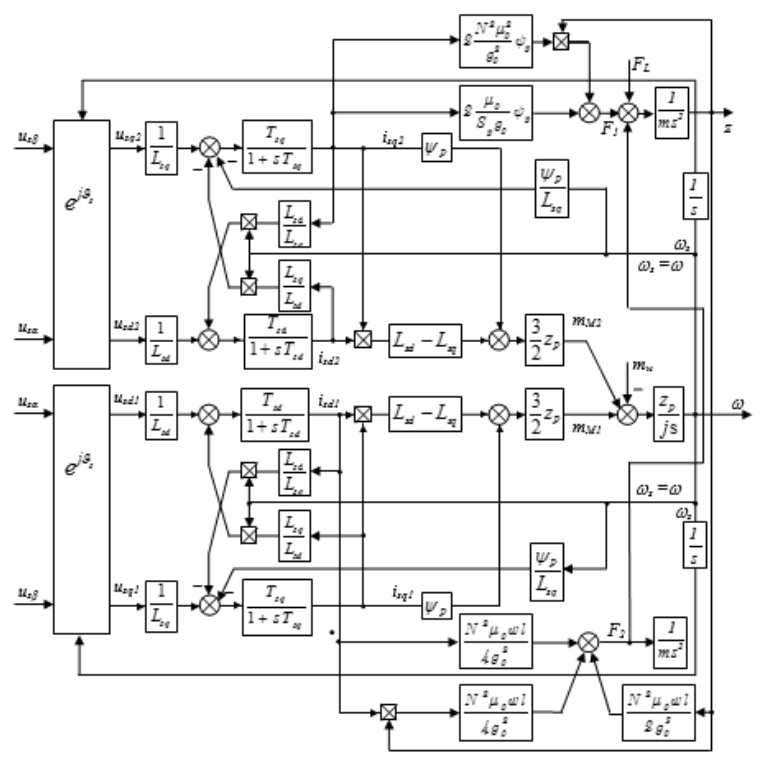

Figure 2: Structure diagram of AFPM motor

\section{The voltage, current and magnetic space vectors of APFM motor in two working areas.}

The voltage, current, and magnetic space vector of AFPM motor in two working areas are presented in Figure $3[1,5,7]$. From (1), it is clearly seen that the torque of AFPM motor includes two parts: the major part with multiplication $\psi_{p} i_{s q}$ and the reactive part due to the difference of stator inductance $\left.\left(L_{s d}-L_{s q}\right) \neq 0\right)$. In all operating condition, the AFPM motor must produce a sub-torque www.astesi.com to compensate the reactive part. The clear existence of the reactive part normally neglected in classical control solutions. Ignoring that component helps to simplify control system and can be accepted in reality within nominal rotational speed, because in that range $i_{s d}=0$ (Figure 3a). On the contrary, in the speed range above the base speed, in order to speed up, the flux must be reduced by applying a negative current $i_{s d}$. The motor is now in flux weakening mode, the current is proportional to the rotor's speed (Figure 3b). This leads to the reactive component of the torque is significant and it can't be ignored.

When the motor's speed is adjusted to above base speed, frequency is greater than the nominal frequency $f_{\text {I Im }}$ but its voltage cannot exceed the nominal voltage $U_{d m}$. The maximum value of voltage is $U_{I}=U_{d m}$. The motor's electromotive force expression shows that the flux is inversely proportional to frequency, this is equivalent with the case that the flux of a DC motor is reduced to speed up.

Unlike the synchronous motor with the permanent magnet attached inside the rotor and reluctance synchronous motor, the AFPM motor operating in nominal speed range maintains the current $i_{s d}=0$. Therefore, we only consider the range of above nominal speed.
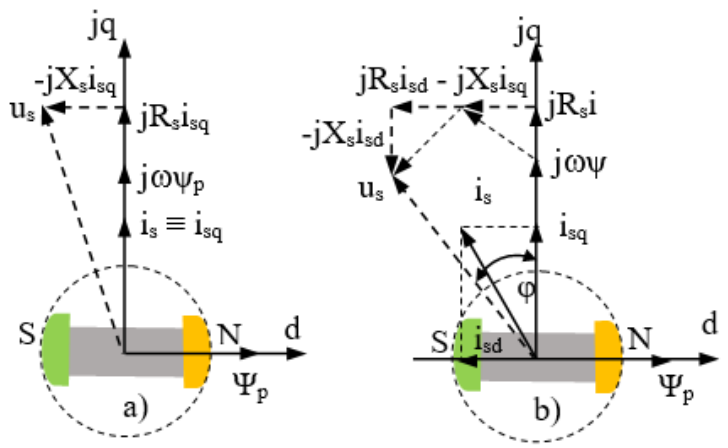

Figure 3: State vector of voltage, current and the magnetic flux of AFPM motor in two working areas: a) Under nominal speed; b) Above nominal speed.

\section{Calculating the critical values of voltage and current:}

Before introducing a variety of control strategies, we need to consider the limitation of current and voltage $[4,5]$. The limitation of current vector:

$$
i_{s}=\sqrt{i_{s d}^{2}+i_{s d}^{2}}<i_{s m}
$$

The current limit of (2) is a circular with radius $i_{s m}$ in plane of $\left(i_{s d}, i_{s q}\right)$

The voltage limit vector: From the formula of the voltage at steady state neglecting the resistance of stator:

$$
u_{s d}=-\omega_{s} L_{s q} i_{s q} ; u_{s q}=\omega_{s} L_{s d} i_{s d}+\omega_{s} \psi_{p}
$$

The fundamental maximum phase voltage of stator is determined by the DC-link voltage:

$$
\left|u_{s}\right|=\sqrt{u_{s d}^{2}+u_{s d}^{2}}<u_{s m}
$$

Where: $u_{s m}$ is the maximum DC voltage applied to the inverter.

$$
u_{s}^{2}=u_{s d}^{2}+u_{s d}^{2}=\left(\omega_{s} L_{s q} i_{s q}\right)^{2}+\left(\omega_{s} L_{s d} i_{s d}+\omega_{s} \psi_{p}\right)^{2}
$$




$$
\frac{u_{s}^{2}}{\omega_{s}^{2}}=\left(L_{s q} i_{s q}\right)^{2}+\left(L_{s d} i_{s d}+\psi_{p}\right)^{2}
$$

From (3) and (4), ignoring the stator resistances in the steady state, the currents $i_{s d}, i_{s q}$ are defined. Substitute them into (1), the motor torque is obtained:

$m_{M}=k_{1}\left(\frac{u_{s}}{\omega_{s}}\right) \cos \varphi-k_{2}\left(\frac{u_{s}}{\omega_{s}}\right)^{2} \sin 2 \varphi$

$k_{1}=\frac{3 z_{p}}{2} \psi_{p}\left(\frac{\left(L_{s d}-L_{s q}\right)}{L_{s d}}-\frac{1}{L_{s q}}\right) ; k_{2}=\frac{3 z_{p}}{2}\left(\frac{L_{s d}-L_{s q}}{L_{s d} L_{s q}}\right)$

where: $\varphi$ is angle between stator voltage vector $u_{s}$ and the $q$ axis.

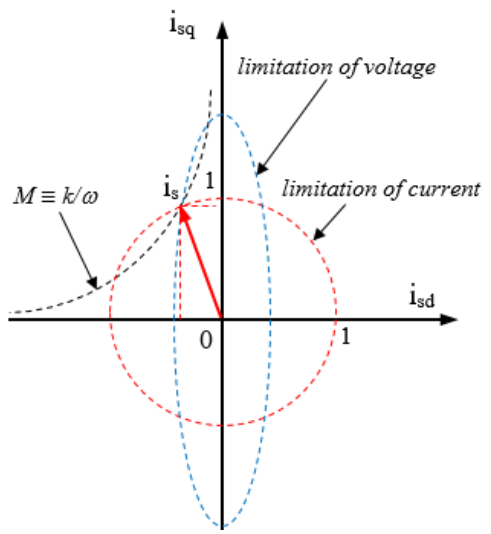

Figure 4: The limits and the optimal point of torque of the AFPM motor above nominal speed

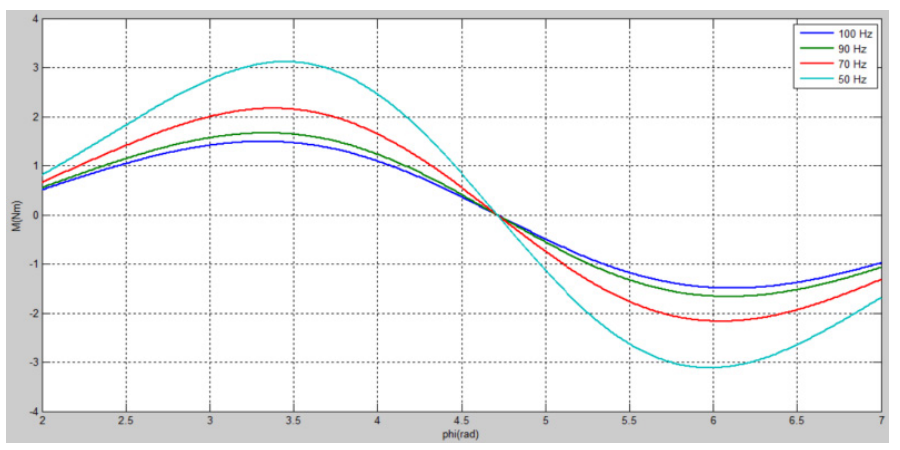

Figure 5: Simulation result of the motor torque with $D C$ voltage $U=400 \mathrm{~V}$;

Figure 5 shows that if frequency is increased to speed up the motor to above base speed, the flux along with $d$ axis will be decreased. However, if $\varphi$ is maintained at $60^{\circ}$ then the motoring torque will be maximum.

\section{Control design for AFPM motor}

\subsection{General control scheme}

In term of structure, AFPM motor is completely different from conventional motors; its control scheme includes two different control loops: rotor displacement control loop (attractive force control) and speed control loop (motoring torque control). The general control scheme of AFPM motor is shown in Figure 6 [1,

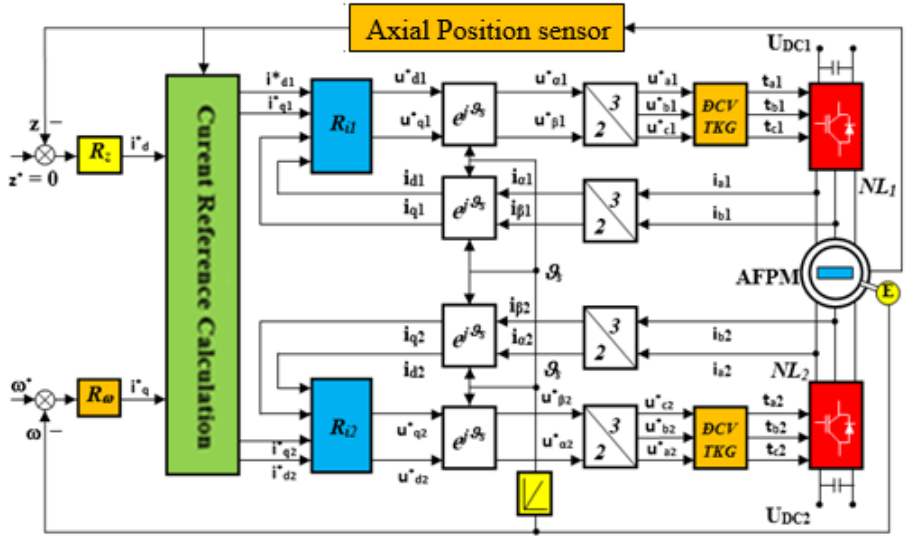

3].

Figure 6: Vector control structure of AFPM motor

Vector control of AFPM motor is based on the analysis of the motor's instantaneous currents into two components: the direct component $i_{\mathrm{d}}$ and the quadrature component $i_{q}$. The direct component generates the attractive forces and the quadrature component generates the motoring torques. By this way, the control scheme of AFPM motor becomes similar to that of a DC motor.

The rotor displacement along $z$ axis from its equilibrium point can be detected by displacement sensor. The detected value is compared to the reference value $z^{*}$ and the difference is inputted to the $\mathrm{R}_{\mathrm{z}}$ controller. The reference $z^{*}$ is always set to make the rotor in-between the two stators at the equilibrium point. The output of $\mathrm{R}_{\mathrm{z}}$ is used to compute the current reference $i_{d}^{*}$. The reference $i_{d 1}^{*}$ and $i_{d 2}^{*}$ of the two stator windings can be calculated by using the compensating current $i_{\mathrm{d} 0}: i_{d 1}^{*}=i_{d 0}+i_{d}^{*} ; i_{d 2}^{*}=i_{d 0}-i_{d}^{*} ; i_{d 0}$ can be zero or a small value around zero.

The rotor speed detected by the encoder is compared with the speed reference, the difference is fed to the speed controller $\mathrm{R}_{\omega}$. The output of $\mathrm{R}_{\omega}$ is used to determine the $q$-axis reference current $i_{q}^{*}$. The $q$-axis reference current of the two stator windings $i_{q 1}^{*}$ and $i_{q 2}^{*}$ is then calculated similar to $i_{d}$.

Control design implemented for AFPM motor includes following loops:

\subsection{Current control}

Most of the modern AC motor drives have a control structure comprising an internal current control loop. Therefore, the drive system characteristic depends on the quality of applied current control strategy $[1,3,4,5]$

The main task of the current control loop is to make the motor's currents follow the reference signals. By comparing the measured currents with the reference currents, the current control loop generates switching states for the inverter in order to decrease the current errors. In general, the current control loop performs two tasks: error compensation (reduce current error) and modulation (determine switching states). 


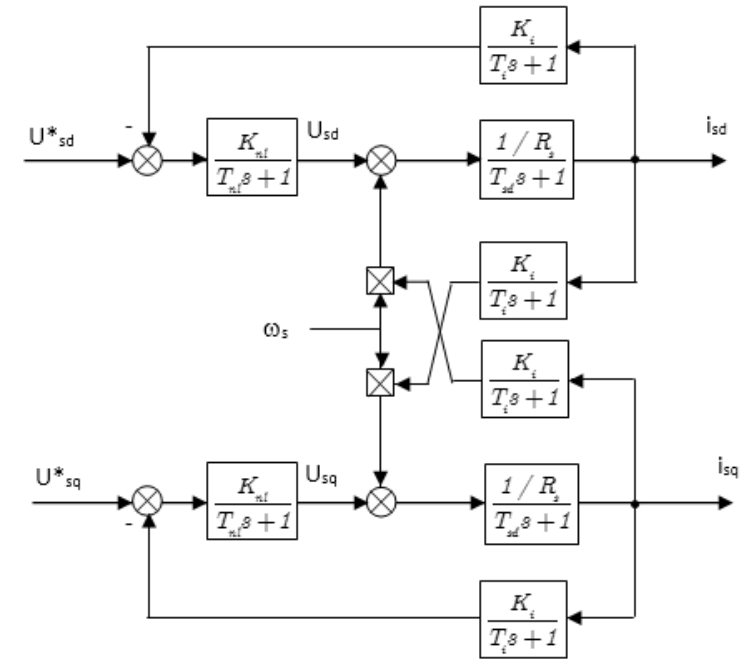

Figure 7: The current control loop of AFPM motor

The current control loop of AFPM motor as mentioned in Figure 7 is extracted from Figure 2 and following formulas:

$$
\begin{gathered}
i_{s d}=\left(u_{s d}+i_{s q} \cdot W_{s} \cdot L_{s q}\right) W_{s d} \\
i_{s q}=\left(u_{s q}-i_{s d} \cdot w_{s} \cdot L_{s d}\right) W_{s q} \\
i_{s d}=\frac{1}{1+W_{s d} \cdot W_{s q} \cdot W_{s}^{2} \cdot L_{s d} \cdot L_{s q}}\left(W_{s d} u_{s d}+w_{s} \cdot L_{s q} \cdot W_{s d} \cdot W_{s q} \cdot u_{s q}\right) \\
i_{s q}=\frac{1}{1+W_{s d} \cdot W_{s q} \cdot W_{s}^{2} \cdot L_{s d} \cdot L_{s q}}\left(-W_{s} \cdot L_{s d} \cdot W_{s d} \cdot W_{s q} \cdot u_{s d}+W_{s q} u_{s q}\right) \\
W(s)=\frac{W_{i} \cdot W_{n l}}{1+W_{s d} \cdot W_{s q} \cdot \omega_{s}^{2} \cdot L_{s d} \cdot L_{s q}}\left[-\omega_{s} \cdot L_{s d} \cdot W_{s d} \cdot W_{s q} \omega_{s} \cdot L_{s q} \cdot W_{s d} \cdot W_{s q}\right] \\
\text { Where: } W_{s d}=\frac{1 / R_{s}}{T_{s d} s+1} ; W_{s q}=\frac{1 / R_{s}}{T_{s q} s+1} ; \\
W_{n l}=\frac{K K_{n l}}{T_{n l} s+1} ; W_{i}=\frac{K_{i}}{T_{i} s+1} .
\end{gathered}
$$

The formulas (7), (8), (9) show that interactive actions exist in current control loop. To obtain desire quality of the closed system, the modulus optimum criterion is applied:

$$
W_{m}(s)=\frac{1}{1+2 T_{s} s+2 d_{s d^{\prime}} T_{s}^{2} s^{2}}
$$

Before applying the modulus optimum criterion, the current control loop must be decoupled.

Decoupling regulators are defined as follows:

$$
\begin{aligned}
& W_{R}(s)=W_{m}(s)\left(I-W_{m}(s)\right)^{-1} \cdot W(s) \\
& T_{s}=T_{s i}=2 T_{i}=0,002
\end{aligned}
$$

Hence, $T_{\sigma}^{2}$ can be ignored. After that, transfer functions of the decoupling regulators for the current control loop can be determined.

$$
\begin{aligned}
& \begin{aligned}
W_{R}(s) & =\frac{1}{4 T_{i} \cdot K_{n l} K_{i}}\left[\begin{array}{cc}
L_{s d}\left(1+\frac{1}{T_{s d} s}\right) & \frac{-\omega_{s} \cdot L_{s q}}{s} \\
\frac{\omega_{s} L_{s d}}{s} & L_{s q}\left(1+\frac{1}{T_{s q} s}\right)
\end{array}\right] \\
& =\left[\begin{array}{ll}
R_{11} & R_{12} \\
R_{21} & R_{22}
\end{array}\right]
\end{aligned} \\
& R_{t 1}(s)=\frac{1}{4 T_{i} \cdot K_{n l} K_{i}} L_{s d}\left(1+\frac{1}{T_{s d} s}\right) \\
& R_{12}(s)=\frac{1}{4 T_{i} \cdot K_{n l} K_{i}} \frac{\omega_{s} L_{s d}}{s} \\
& R_{21}(s)=\frac{1}{4 T_{i} \cdot K_{n l} K_{i}} \frac{-\omega_{s} L_{s d}}{s} \\
& R_{22}(s)=\frac{1}{4 T_{i} \cdot K_{n l} K_{i}} L_{s q}\left(1+\frac{1}{T_{s q} s}\right)
\end{aligned}
$$

Insert the decoupling regulators into the current loop diagram in Figure 7 we have the decoupled diagram as shown in Figure 8.

\subsection{Axial displacement control}

For simplicity, assume that the radial movement of the rotor is supported by two ideal radial magnetic bearings. Thus, the axial displacement and the radial displacement are independent, and can be expressed as follows $[1,2,3,4]$ :

$$
F-F_{L}=m \ddot{z}
$$

where $m$ is the weight of the motion part and $F$ is the axial force.

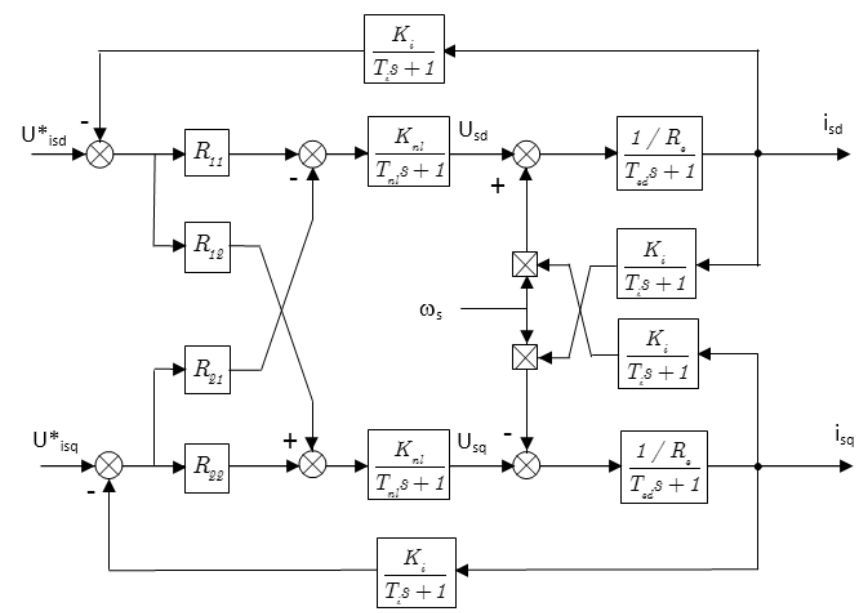

Figure 8: Decoupled current control loop

The equation (15) is obtained by substituting (1) into (14):

$$
\begin{aligned}
m \ddot{z}+F_{L} & =k_{1}\left(i_{2 d}-i_{1 d}\right)+k_{1}\left(i_{2 d}-i_{1 d}\right) z-k_{2} z \\
k_{1} & =2 \frac{\mu_{0}^{2} N^{2}}{g_{0}^{2}} \psi_{p} ; k_{2}=2 \frac{\mu_{0}}{S_{p} g_{0}} \psi_{p}^{2} .
\end{aligned}
$$

It is easy to see that this system is unstable. To make the system stable, a controller with derivative component is used. The axial displacement control loop is shown in Figure 9. 
The axial displacement control loop contains the transfer function of the current control loop. Since the torque load is usually undefined, so it is regarded as an external interference.

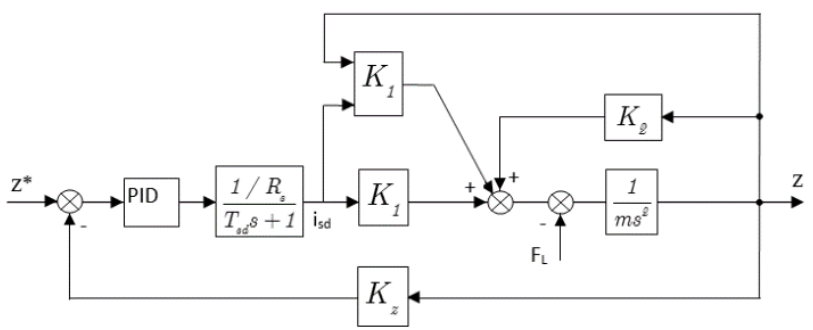

Figure 9: Axial displacement control loop

To eliminate the steady state error, a PID controller is used.

$$
G_{c z}(s)=K_{P}+\frac{K_{I}}{s}+K_{D} s
$$

The system will be stable if the controller parameters satisfy the following conditions:

$$
\left\{\begin{array}{l}
K_{P}>\frac{K_{2}}{K_{1} K_{z}} \\
K_{I}<\frac{K_{D}\left(K_{1} K_{P}+K_{2}\right)}{m} \\
K_{I}>0 \\
K_{D}>0
\end{array}\right.
$$

\subsection{Speed control}

For all types of electric motor, the difference between electromagnetic torque $M$ and torque load $M_{L}$ causes the acceleration of the rotor according to the mechanical characteristic of the motor drive. The rotational motion equation can be written as follows $[1,3,4,5]$ :

$$
M-M_{L}=J \frac{d \omega}{d t} \quad \frac{\omega}{M-M_{L}}=\frac{1}{J_{S}}
$$

$\mathrm{M}$ can be controlled by the $q$-axis current $i_{q}$ as shown in (1); thus, the speed control loop is depicted in Figure 10.

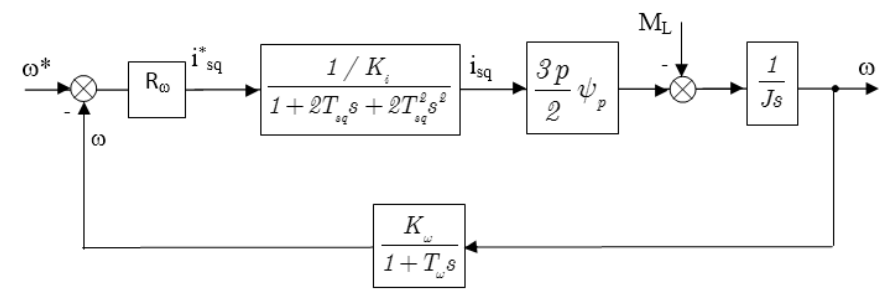

Figure 10: Speed control loop

Similar to the axial displacement control loop, the speed control loop also includes an inner current control loop and a fixed motor transfer function. Due to the uncertain load, in the first step $\mathrm{M}_{\mathrm{L}}$ is regarded as an external disturbance of the system. The influence of the speed measurement is usually included in the equivalent time constant of the current control loop.
Hence, the closed-loop transfer function can be expressed as follow:

$$
\mathrm{W}_{K}(s)=\frac{R_{\omega} \mathrm{W}_{0}}{1+R_{\omega} \mathrm{W}_{0}}=\frac{K R_{\omega}}{s\left(T_{s}^{\prime} s+1\right)+K R_{\omega}}
$$

Apply the symmetrical optimum criterion for the speed control loop:

$$
\mathrm{W}_{C}(s)=\frac{1+4 T_{s} s}{1+4 T_{s} s+8 T_{s}^{2} s^{2}+8 T_{s}^{3} s^{3}}
$$

Equalizing (19) and (20), we have:

$$
\frac{K R_{\omega}}{s\left(T_{s}^{\prime} s+1\right)+K R_{\omega}}=\frac{1+4 T_{s} s}{1+4 T_{s} s+8 T_{s}^{2} s^{2}+8 T_{s}^{3} s^{3}}
$$

Choose: $2 \mathrm{~T}_{\mathrm{s}}{ }=\mathrm{T}_{\mathrm{s}}$, solve the above equation we have:

$$
R_{\omega}=\frac{1+4 T_{s} s}{K 8 T_{s}^{2} s}=\frac{1}{8 K T_{s}^{2} s}+\frac{1}{2 K T_{s}}
$$

\section{Quality evaluation by numerical simulation}

\subsection{Specifications of the motor and simulation parameters}

$$
\mathrm{R}_{\mathrm{s}}=2,3 \Omega ; \mathrm{L}_{\mathrm{sq}}=9,6 \cdot 10^{-6} \mathrm{H} ; \mathrm{L}_{\mathrm{sd}}=8,2 \cdot 10^{-6} \mathrm{H} \text {; }
$$

$\mathrm{T}_{\mathrm{sq}}=4,2 \cdot 10^{-6} ; \mathrm{T}_{\mathrm{sd}}=3,56 \cdot 10^{-6} ; \Psi_{\mathrm{p}}=0,0126 \mathrm{~Wb} ;$

$\mathrm{Z}_{\mathrm{p}}=1 ; \mathrm{g}_{0}=1,7 \cdot 10^{-3} \mathrm{~m} ; \mathrm{m}_{\text {rotor }}=0,235 \mathrm{~kg}$;

$\mathrm{J}_{\mathrm{r}}=0,0000082 \mathrm{kgm}^{2} ; \mu_{0}=4 \pi \times 10^{-7} \mathrm{H} / \mathrm{m} ;$

$\mathrm{Knl}=5 ; \mathrm{K}_{\mathrm{i}}=1 ; \mathrm{T}_{\mathrm{i}}=0,001 ; \mathrm{K}_{\omega}=0,00417 ;$

$\mathrm{T}_{\omega}=0,1 ; \mathrm{T}_{\mathrm{s} \omega}=\mathrm{T}_{\omega}+2 \mathrm{~T}_{\mathrm{i}} ; 2 \mathrm{~T}_{\mathrm{s}}{ }_{\mathrm{s}}=\mathrm{T}_{\mathrm{s} \omega}$.

\subsection{The simulation diagram of AFPM motor}

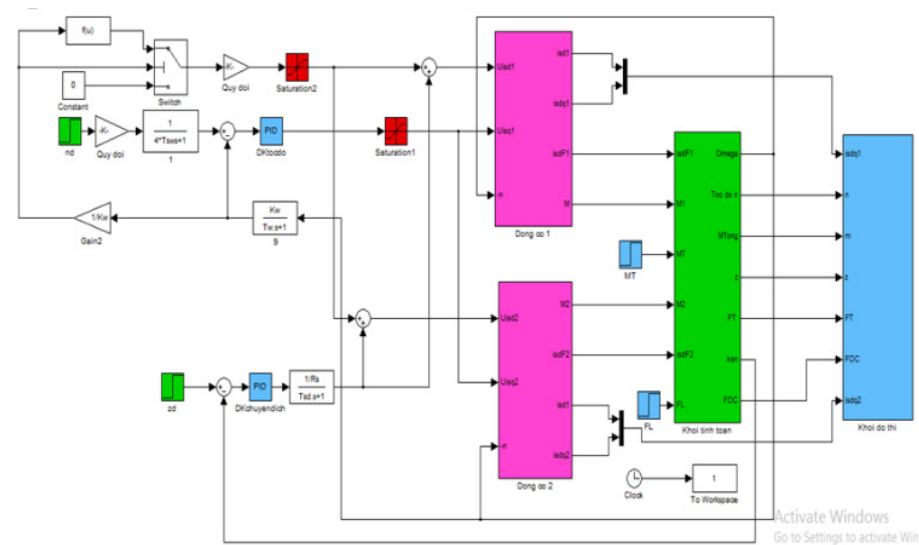

Figure 11: Simulink model of AFPM motor

\subsection{Simulation results}

+ When the motor operates at the nominal speed: $n=3000 \mathrm{rpm}$; $m=0,08 \mathrm{Nm}$; displacement $z=0$ 
X. M. Tran et. al. / Advances in Science, Technology and Engineering Systems Journal Vol. 2, No. 3, 153-159 (2017)

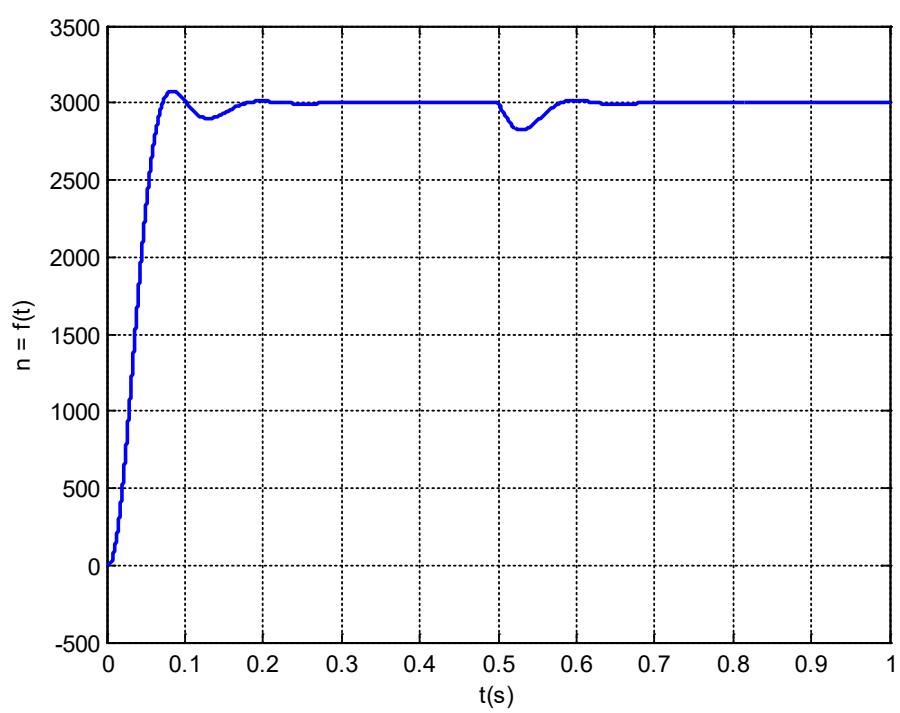

+ When the motor operates above the nominal speed:

$n=4000 \mathrm{rpm} ; m=0,08 \mathrm{Nm} ; z \neq 0$
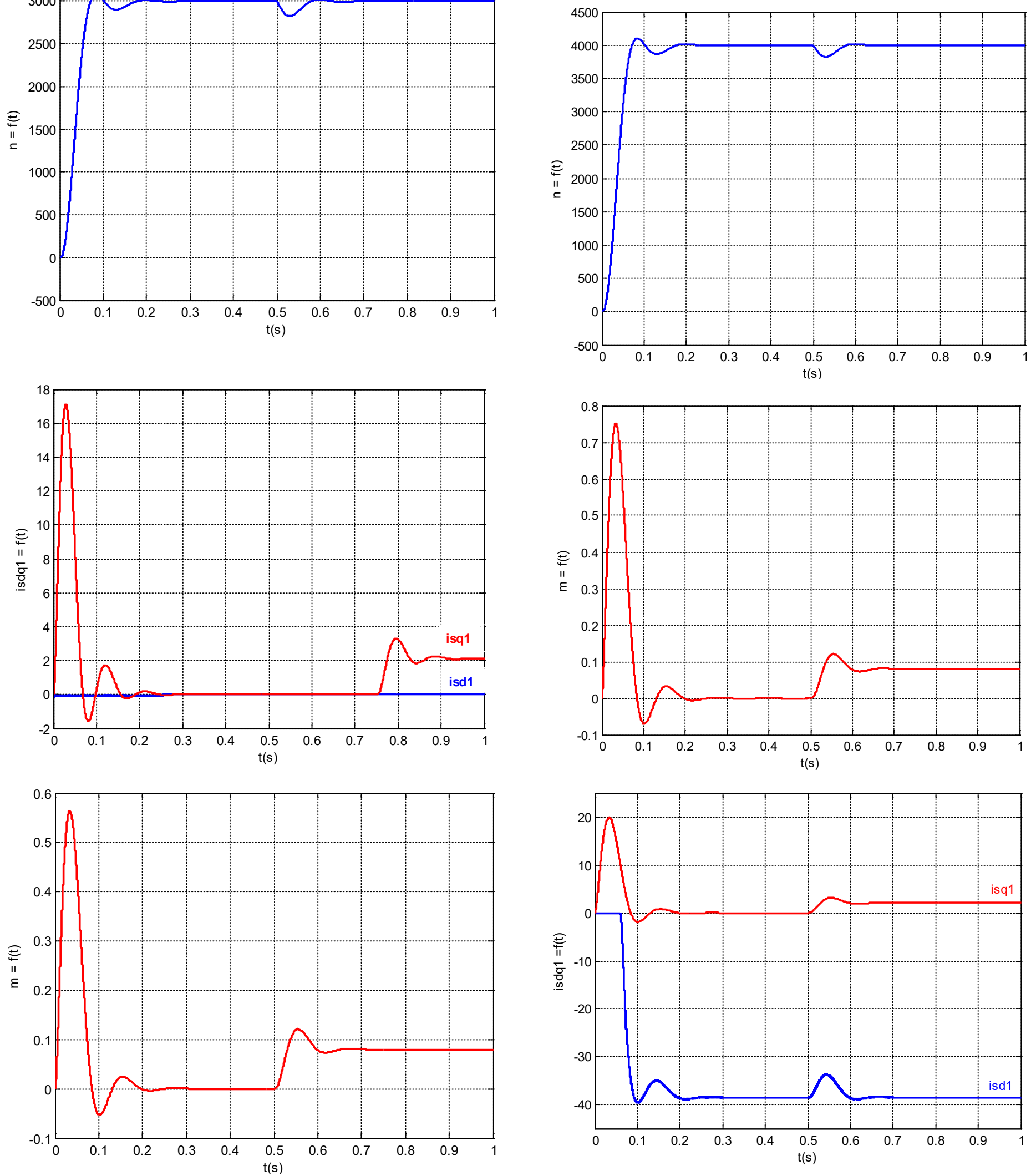

Figure 12: Characteristics of AFPM motor when it operates at the nominal speed and no axial force: $n=3200 \mathrm{rpm}$, displacement $z=0$; the torque $m$ (has the same shape as the current $\left.i_{s q}\right) ; i_{s d}=0$

Figure 13: Characteristics of AFPM motor when it operates above the nominal speed: $n=4000 \mathrm{rpm}, z \neq 0$; the torque $m$ (has the same shape as the current $i_{s q}$ ); $i_{\text {sd }}$ has large negative value. 


\section{Conclusions}

The AFPM motor with special structure is used in combination with magnetic bearings to form a system which includes two control loops: the speed control loop and the rotor displacement control loop (with assumtion that the magnetic bearings fullfil their nominal functions). By using rotor flux oriented control method, some results are firstly achieved:

- Speed control above the nominal speed is attained by flux weakening thank to apply a current $i_{s d}$ opposite in direction with the flux $\psi_{p}$ while sustaining the torque.

- The rotor is always kept at the center of the motor by the rotor axial displacement control loop.

- Further research need to be implemented in order to improve the control quality and sustain the optimal torque when the flux is weakened.

- Experimental study on the AFPM motor.

\section{References}

[1] Nguyen Phung Quang and Jörg-Andreas Dittrich, "Vector Control of ThreePhase AC Machines", springer

[2] Akira Chiba, adashi Fukao, Osamu Ichikawa, Masahide Oshima, asatsugu Takemoto and David G. Dorrell, "Magnetic Bearings and Bearingless Drives", Newnes, 2005.

[3] Quang Dich Nguyen and Satoshi Ueno, "Analysis and Control of Non-Salient Permanent Magnet Axial-Gap Self-Bearing Motor", IEEE Transactions on Industrial Electronics, Vol. PP, No. 99, pp. 1-8, 2010 (early access).

[4] Nguyen Van Lien, Nguyen Manh Tien, Doan Quang Vinh, "Control of AC motor with magnetic from semiconductor inverter" NXB KHKT, 2005.

[5] Nguyen Duc Quan,"Modeling, simulation, and control reluctance high speed motor, Journal of Science and Technology - Da Nang University - No 11(96).2015 Book 2.

[6] Nguyen Doan Phuoc: "Nonlinear control theory". NXB KH\&KT, 2007.

[7] Trong Duy Nguyen, Gilbert Foo Hock Beng, King-Jet Tseng, Don Mahinda Vilathgamuwa, and Xinan Zhang: "Modeling and Position-Sensorless Control of a Dual-Airgap Axial Flux Permanent Magnet Machine for Flywheel Energy Storage Systems“, Journal of Power Electronics, Vol. 12, No. 5, September 2012. 